\title{
Expression of cold-inducible RNA-binding protein (CIRP) in renal cell carcinoma and the effect of CIRP downregulation cell proliferation and chemosensitivity to gemcitabine
}

\author{
KE-WEN ZHOU ${ }^{1}$, KUN JIANG ${ }^{2}$, WEIZHI ZHU ${ }^{1}$ and GUOBIN WENG ${ }^{1}$ \\ ${ }^{1}$ Department of Urology, Ningbo Urology and Kidney Hospital, Ningbo, Zhejiang 315100; \\ ${ }^{2}$ Department of Urology, Ren Min Hospital, Wuhan University, Wuhan, Hubei 430071, P.R. China
}

Received October 24, 2016; Accepted January 21, 2018

DOI: $10.3892 / \mathrm{ol} .2018 .8338$

\begin{abstract}
The aim of the present study was to investigate the expression of cold-inducible RNA-binding protein (CIRP) in renal cell carcinoma (RCC) and to determine the effects of downregulation of CIRP on cell proliferation and chemosensitivity to gemcitabine. The expression of CIRP was detected by western blot analysis, quantitative polymerase chain reaction and immunohistochemistry (IHC) in 17 RCC and peri-cancerous tissue samples. Subsequently, the RCC 786-0 cell line was selected in order to investigate the function of CIRP using RNA interference (RNAi) technology, which was able to inhibit the expression of CIRP in vitro. Furthermore, the chemosensitivity to gemcitabine of each group [CIRP small interfering RNA (siCIRP), negative control small interfering RNA (siNC) and blank control] was compared. There were marked differences between the RCC and peri-cancerous tissues. IHC demonstrated that the CIRP expression in 13/17 (76.50\%) tumor samples was markedly positive compared with that in the peri-cancerous tissues and the most common pathological type was clear cell RCC (92.30\%). This observation was further confirmed through western blot analysis of protein expression levels. CIRP downregulation by RNAi in the RCC 786-0 cell line significantly decreased RCC proliferation. Additionally, when RNAi was coupled with gemcitabine treatment, there was a significant increase in apoptosis in the siCIRP group. CIRP was overexpressed in RCC tissues and in the 786-0 cell line. Downregulation of CIRP by siRNA inhibited the proliferation of the 786-0 cell line and enhanced the chemosensitivity of the cells to gemcitabine. Therefore, CIRP downregulation may provide a novel pathway for the treatment of metastatic RCC.
\end{abstract}

Correspondence to: Dr Guobin Weng, Department of Urology, Ningbo Urology and Kidney Hospital, 1 Qian He Road, Yin Zhou, Ningbo, Zhejiang 315100, P.R. China

E-mail: ddguobinweng@163.com

Key words: cold-inducible RNA-binding protein, renal cell carcinoma, chemosensitivity, gemcitabine

\section{Introduction}

The prognosis of patients affected by metastatic renal cell carcinoma (mRCC) has improved markedly with targeted therapies. However, 20-25\% of these patients are refractory to treatment at the first response assessment and the majority of patients will acquire drug resistance during treatment. RCC was previously considered to be resistant to chemotherapy on the basis that the results of phase II trials had not always been promising. However, at present, chemotherapy may serve important roles in the development of novel treatment strategies that target different mechanisms of action, particularly in situations without other effective therapeutic options, including primary and secondary resistance to targeted therapy, tumors with poor prognoses and sarcomatoid histology (1).

CIRP is a highly conserved glycine-rich RNA-binding protein, which contains an amino-terminal consensus sequence RNA-binding domain and a carboxyl-terminal glycine-rich domain (2). CIRP may be induced by mild temperatures $\left(32^{\circ} \mathrm{C}\right)$, DNA damage, hypoxia and oxidative stress inducers (3). Upon stress induction, CIRP shuttles from the nucleus to the cytoplasm to stabilize target mRNAs $(4,5)$. CIRP mediates suppression of cell proliferation with prolongation of the G1 phase and contributes to the suppression of apoptosis induced by tumor necrosis factor- $\alpha$ (6). CIRP also contributes to the maintenance of normal cellular function $(7,8)$.

The precise function of CIRP in the cancer cell microenvironment remains unclear. Previous studies have identified CIRP as a novel oncogene that may facilitate the proliferation of tumor cells via its upregulated expression in various tumor cells and its further inhibition of oxidative-induced tissue damage, enabling it to exert a trophic role in oncogenesis (9). Ren et al (10) observed that CIRP was overexpressed in oral squamous cell carcinoma, which may be associated with the poor prognosis of this disease. Hamid et al (11) observed that CIRP participated in the cell cycle regulation of normal human endometrium and loss of its expression may be involved in endometrial carcinogenesis. Wang et al (12) observed that the expression of CIRP in pituitary adenoma was closely associated with tumor proliferation and invasion, and that its significantly elevated expression level indicates post-operative recurrence. 
Another study revealed that CIRP may be involved in the occurrence of hepatocellular carcinoma (13). In vitro, the expression of CIRP was observed in Hep-G2, NC65, HeLa, T24 and NEC8 cell lines (14). Additionally, Zeng et al (15) demonstrated that downregulation of cold shock protein [which contains CIRP and RNA-binding motif protein 3 (RBM3)] impairs the proliferation and the enhances chemosensitivity of prostate cancer cells. However, the role of CIRP expression in RCC clinical tumor samples and in RCC cell lines remains unclear.

The present study investigated the expression of CIRP in RCC tissues and in a cell line in order to examine the potential chemosensitivity of the cells to gemcitabine. A siRNA approach was used to examine the proliferation of the 786-0 cell line in vitro. The results suggested a potential novel mechanistic pathway for RCC therapy.

\section{Materials and methods}

Patient clinical characteristics. RCC and peri-cancerous tissue samples from 17 patients were obtained from the Department of Urology at Ningbo Urology and Kidney Hospital (Ningbo, China) between January 2014 and December 2014. The patient population comprised 7 females and 10 males, aged between 31 and 77 years (mean, 54.6 years). The pathological types included clear cell RCC ( $\mathrm{n}=14,82.35 \%)$, chromophobe renal carcinoma $(n=1)$, papillary carcinoma $(n=1)$ and vascular leiomyoma $(n=1)$. The present study was approved by the Ethics and Scientific Committee of Ningbo Urology and Kidney Hospital and written informed consent was obtained from all participants.

Cell culture and treatment. The clear cell RCC 786-0 cell line was obtained from American Type Culture Collection (ATCC; Manassas, VA, USA). The cells were cultured at $37^{\circ} \mathrm{C}$ in $5 \% \mathrm{CO}_{2}$ in RPMI-1640 medium (Hyclone; GE Healthcare Life Sciences, Logan, UT, USA), supplemented with $10 \%$ fetal bovine serum (Gibco; Thermo Fisher Scientific, Inc., Waltham, MA, USA). 786-0 cells were treated with different concentrations $(0.05,0.10,0.25,0.75,1.00,5.00,10.00,20.00,30.00$ and $40.00 \mathrm{nM}$ ) of gemcitabine $72 \mathrm{~h}$ after transfection.

siRNA transfections. CIRP small interfering RNA (siCIRP) was obtained from Shanghai GenePharma Co., Ltd. (Shanghai, China), with the sequences: Sense, 5'-CCAGAGAUCUCG GGGAUUUUU-3, and antisense, 5'-PAAAUCCCCGAGAUC UCUGGUU-3'. RCC 786-0 cells were transfected with $33 \mathrm{nM}$ siRNA at a total oligo concentration of $150 \mathrm{nM}$, using $10 \mu \mathrm{l}$ Lipofectamine 2000 (Invitrogen; Thermo Fisher Scientific, Inc.), and were plated simultaneously onto 6-well plates. Chemical treatments of gemcitabine (concentrations were $0.05,0.10,0.25$, $0.75,1.00,5.00,10.00,20.00,30.00$ and $40.00 \mathrm{nM})$ were conducted $24 \mathrm{~h}$ after transfections in 96-well plates.

Western blot analysis. Cells and tissues were lysed in a triple detergent RIPA buffer (Beyotime Institute of Biotechnology, Haimen, China) containing a protease inhibitor cocktail. Protein ( $40 \mu \mathrm{g}$, which was determined by BCA method) was separated by $12 \%$ SDS-PAGE and transferred onto polyvinylidene fluoride membranes. The membranes were blocked with 5\% skimmed milk at room temperature for $1 \mathrm{~h}$, prior to being incubated with an anti-CIRP antibody (cat. no., 10209-2-AP; dilution, 1:1,000; ProteinTech Group, Inc., Chicago, IL, USA) and either an anti-GAPDH antibody (for the cells; dilution; 1:3,000; Bioworld Technology, Inc., St. Louis Park, MN, USA) or an anti- $\beta$-actin antibody (for the tissues; dilution; 1:100; cat. no. ab8226; Abcam, Cambridge, UK) at $4{ }^{\circ} \mathrm{C}$ overnight. Following incubation with the secondary antibody (fluorescein-conjugated goat anti-mouse IgG H\&L; cat ab6785; Abcam) at room temperature for $45 \mathrm{~min}$, signals were visualized using enhanced chemiluminescence [cat.no. NEL103001EA; Western Lightning ${ }^{\circledR}$ Plus-ECL, Enhanced Chemiluminescence Substrate, PerkinElmer, Inc., Waltham, MA, USA].

Cell proliferation detection. A total of 5,000 cells/well were seeded onto 96-well plates. Next, $72 \mathrm{~h}$ after gemcitabine treatment (as aforementioned; 0.05-40 nM), $10 \mu \mathrm{l}$ Cell Counting kit-8 (CCK-8; Boster Biological Technology, Pleasanton, CA, USA) was added to each well, according to the manufacturer's protocol. After $4 \mathrm{~h}$ incubation at $37^{\circ} \mathrm{C}, \mathrm{CCK}-8$ absorbance was measured at $450 \mathrm{~nm}$.

Immunohistochemistry. RCC specimens were fixed in $10 \%$ neutral-buffered formalin (Wuxi Zhanwan Chemicals, Yixing, China) at room temperature for 1 week prior to sectioning, and then embedded in paraffin and sectioned at a thickness of $3 \mu \mathrm{m}$, Endogenous peroxidase activity was blocked by incubation with $3 \% \mathrm{H}_{2} \mathrm{O}_{2}$ in PBS at room temperature for 5-10 min, and a standard streptavidin/peroxidase (secondary antibody goat anti-Mouse IgG; cat ab6785, Abcam; incubated at $37^{\circ} \mathrm{C}$ for $15 \mathrm{~min}$; dilution, 1:1,000) complex method (SP) was used for immunostaining. A rabbit anti-CIRBP polyclonal antibody (incubated at $37^{\circ} \mathrm{C}$ for $1.5 \mathrm{~h}$; cat. no., 10209-2-AP; dilution, 1:100; ProteinTech Group. Inc.) was used to assess the presence of CIRP. Following counterstaining $\left(37^{\circ} \mathrm{C}\right.$ for $\left.1 \mathrm{~min}\right)$ of the cell nucleus with hematoxylin, the slides were observed under an optical microscope (x100). One kidney peri-cancerous tissue obtained from surgery was used as a positive and negative control (without primary antibody). Immunopositivity criterion for CIRP was defined as the presence of $\geq 1$ stained cell with a clearly outlined cytoplasm.

Reverse transcription-quantitative polymerase chain reaction $(R T-q P C R)$. Part of the material obtained at the time of surgery was immediately stored at $-80^{\circ} \mathrm{C}$ for subsequent RNA extraction. For total RNA isolation, TRIzol ${ }^{\circledR}$ Reagent (cat no. A33250; Thermo Fisher Scientific, Inc.) was used, according to the manufacturer's protocol. Total RNA was quantified using spectrophotometry (BioSpec-nano; Shimadzu Corp., Kyoto, Japan) at $260 \mathrm{~nm}$. Following the adjustment of RNA concentrations between samples, all RNA samples were reverse transcribed to cDNA according to the manufacturer's protocol (Thermo Fisher Scientific, Inc.; RevertAid First Strand cDNA Synthesis Kit; cat no. K1622). The final volume of each reaction was $20 \mu \mathrm{l}$ and was comprised of RNA isolated by a modified guanidinium thiocyanate method followed by poly (A)+RNA selection with two rounds of oligo (dT)-cellulose columns. RT-qPCR analysis was performed in a total volume of $20 \mu \mathrm{l}$, using a $2 \mathrm{xTaqman}^{\circledR}$ Universal PCR Master mix (cat.no. 439016; Applied Biosystems; Thermo Fisher Scientific, 
Inc.) and $100 \mathrm{nM}$ CIRP primer (forward primer, 5'-CGTGGG TTCTCTAGAGGAGGA-3', and reverse primer, 5'-ACTCTG ACTCCGGCTGCTAT-3'). As an endogenous control, the reference gene GAPDH (forward primer, 5'-ACCACAGTC CATGCCATCAC-3', and reverse primer, 5'-TCCACCACC CTGTTGCTGTA-3') was amplified to normalize results and to allow relative quantitative analysis of CIRP gene expression, and cDNA obtained from peri-cancerous tissue was used as a calibrator. Samples without cDNA were used as negative controls. The reactions were performed $\left(95^{\circ} \mathrm{C}\right.$ for $30 \mathrm{sec}$, then $62^{\circ} \mathrm{C}$ for $40 \mathrm{sec}$ ) at least twice in a PCR thermocycler (StepOne Plus $^{\mathrm{TM}}$ Real Time PCR system; Applied Biosystems; Thermo Fisher Scientific, Inc.). Results were obtained as the number of PCR cycles required to achieve the initial level of fluorescence emission, with values expressed as quantification cycle (Cq). cDNA relative expression (normalized concentration of target gene relative to the reference gene) was provided by the following formula: $2^{-\Delta \Delta \mathrm{Cq}}(16)$, where $\Delta \Delta \mathrm{Cq}=(\mathrm{Cq}$ of CIRP gene-Cq of GAPDH gene, in samples)-(Cq of CIRP gene-Cq of GAPDH gene, in calibrator-renal peri-cancerous tissues).

Flow cytometry. For cell cycle phase analysis, cells were fixed in $70 \%$ ethanol for $30 \mathrm{~min}$ at $-20^{\circ} \mathrm{C}$ followed by washing with phosphate-buffered saline and centrifugation $\left(4^{\circ} \mathrm{C}\right.$ for $5 \mathrm{~min}$ at $200 \mathrm{x} \mathrm{g}$ ). In order to label DNA, pellets were resuspended in Vindelöv solution [3.5 $\mu \mathrm{M}$ Tris- $\mathrm{HCl}(\mathrm{pH} 7.6), 10 \mathrm{mM} \mathrm{NaCl}$, $10 \mu \mathrm{g} / \mathrm{ml}$ propidium iodide (PI), $20 \mu \mathrm{g} / \mathrm{ml}$ RNase and $0.1 \% \mathrm{v} / \mathrm{v}$ NP40] and were incubated in the dark for $20 \mathrm{~min}$ on ice. Cell cycle analysis was performed by flow cytometry analysis using a FACScan flow cytometer (BD Biosciences, Franklin Lakes, NJ, USA), counting in total $1 \times 10^{4}$ cells. Gating of G0/G1 and G2/M populations was performed manually using the CellQuest Pro software (version 5.1; BD Biosciences). Annexin V-fluorescein isothiocyanate (FITC) and PI (BD Pharmingen; BD Biosciences) double staining was performed to discriminate and quantify cell death induced by apoptosis or necrosis. Cell density was adjusted to $1 \times 10^{6} / \mathrm{ml}$. After the cells had been resuspended twice in $100 \mu \mathrm{l}$ binding buffer (Annexin V FITC Apoptosis Detection Kit; BD Pharmingen; BD Biosciences; cat no. 556547), $10 \mu \mathrm{l}$ Annexin V-FITC was added with gentle mixing and the cells were incubated on $4^{\circ} \mathrm{C}$ in the dark for $15 \mathrm{~min}$. The labeled cells were then added to $5 \mu \mathrm{l} \mathrm{PI}$ in $300 \mu \mathrm{l}$ binding buffer and were gently mixed prior to immediate analysis with a FACScan flow cytometer. A total of 10,000 cells were analyzed per sample. Data were recorded and processed using the CellQuest software.

Statistical analysis. Statistical analyses were performed using SPSS software 17.0 (SPSS, Inc., Chicago, IL, USA) and all data are presented as the mean \pm standard deviation. One-way analysis of variance, followed by Tukey's post-hoc test, or Student's t-test was used to test for statistical significance. $\mathrm{P}<0.05$ was considered to indicate a statistically significant difference.

\section{Results}

CIRP is overexpressed in RCC, particularly in clear cell $R C C$. CIRP was overexpressed in RCC tissues compared with expression in peri-cancerous tissues (Fig. 1), and that the majority of cases $(92.30 \%)$ were clear cell RCC. Additionally,

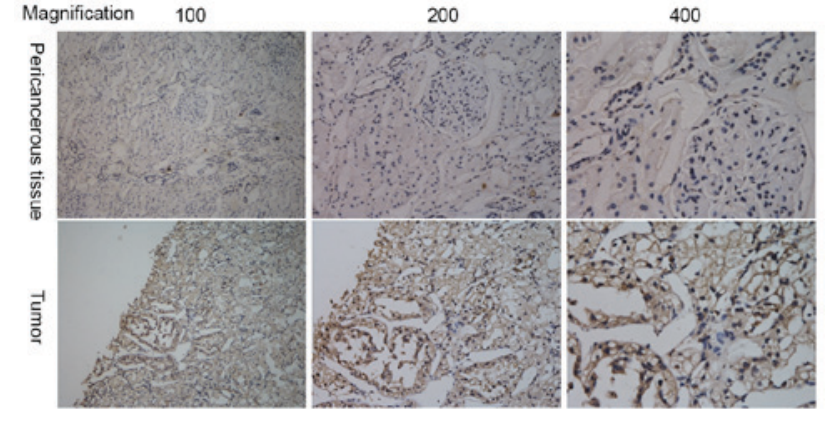

Figure 1. Immunohistochemistry. CIRP was primarily located in the cell cytoplasm in RCC, and CIRP was highly expressed in RCC samples compared with that in peri-cancerous tissues. cold-inducible RNA-binding protein; RCC, renal cell carcinoma.

it was observed that CIRP was primarily located in the cell cytoplasm in RCC. To further explore the differential expression of CIRP between RCC and peri-cancerous tissues, western blotting was performed.

The difference in expression of CIRP mRNA between tumor samples and peri-cancerous tissues was compared using qPCR. The results demonstrated that CIRP was overexpressed in tumor samples $(\mathrm{P}<0.05$; Fig. 2). A total of 11/14 (78.57\%) clear cell RCC samples exhibited positive CIRP expression, and the total CIRP mRNA level in the tumor samples was significantly higher than that in the peri-cancerous tissues $(\mathrm{P}<0.05)$. Western blot analysis also demonstrated that the level of CIRP protein in the tumor samples was significantly higher than that in the peri-cancerous tissues $(\mathrm{P}<0.05$; Fig. 3).

SiRNA-mediated downregulation of CIRP impairs cell proliferation. The expression of CIRP was significantly decreased 3 days after transfection with $100 \mathrm{nM}$ siRNA (total oligo concentration, $150 \mathrm{nM}$; $\mathrm{P}<0.05$; Fig. 4). Additionally, knockdown of CIRP inhibited the proliferation of the RCC 786-0 cell line. Furthermore, a WST-1 assay was used to detect cell proliferation 1-5 days after transfection, and the results demonstrated that the cell proliferation of the siCIRP group was significantly decreased, compared with that of the siNC group $(\mathrm{P}<0.05$; Fig. 5A).

Reducing the expression of CIRP enhances the chemosensitivity of 786-0 cells to gemcitabine. Cells were transfected with siRNAs (siCIRP/siNC) prior to being treated with gemcitabine for a further $72 \mathrm{~h}$. Following transfection with siCIRP, the chemosensitivity of 786- 0 cells to gemcitabine was enhanced compared with that of the cells transfected with siNC. When the concentration of gemcitabine was between 0.25 and $1.0 \mathrm{nM}$, this difference was significant $(\mathrm{P}<0.05)$ and when the concentration of gemcitabine was $>5 \mathrm{nM}$, no differences were observed between the two groups ( $\mathrm{P}>0.05$; Fig. $5 \mathrm{~B})$.

CIRP may exhibit little impact on the cell cycle and cell apoptosis. Cells were transfected with siRNAs (siCIRP/siNC) and were cultured for $48 \mathrm{~h}$. Flow cytometry was subsequently used to detect the impact of CIRP on the cell cycle and cell apoptosis. The cell cycle and cell apoptosis of the two groups (siCIRP/siNC) exhibited no significant differences $(\mathrm{P}>0.05$; Table I; Fig. 6). 


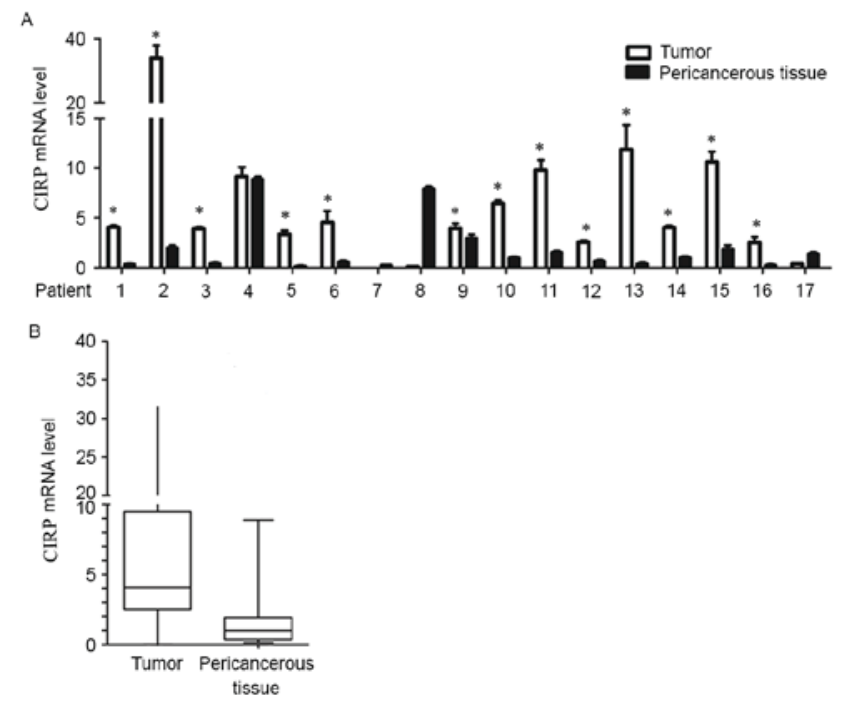

Figure 2. mRNA levels as determined by quantitative polymerase chain reaction. (A) CIRP mRNA was highly expressed in tumor samples compared with peri-cancerous samples. (B) The total CIRP mRNA levels in the tumor samples were higher than those in the peri-cancerous tissues $\left({ }^{*} \mathrm{P}<0.05\right)$. CIRP, cold-inducible RNA-binding protein.

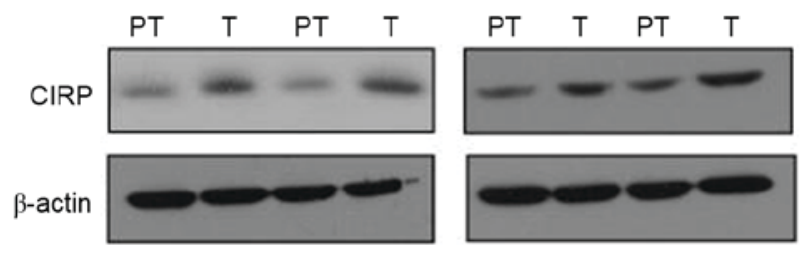

Figure 3. Western blot analysis. The level of CIRP protein in tumor samples was higher compared with that in the peri-cancerous tissues $(\mathrm{P}<0.05)$. CIRP, cold-inducible RNA-binding protein; T, tumor samples; PT, peri-cancerous tissues.

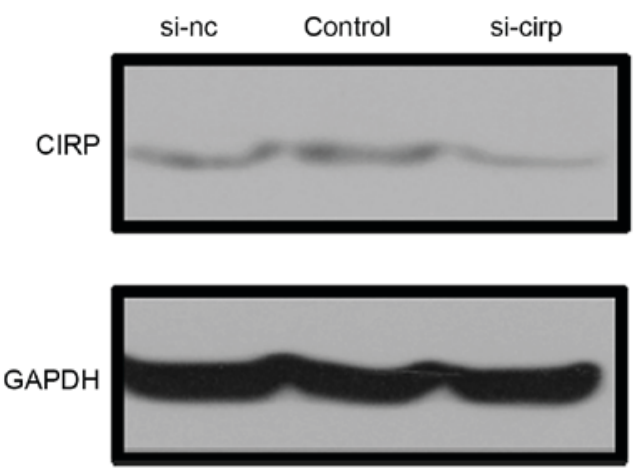

Figure 4. The effect of CIRP siRNA. CIRP was normally expressed in the 786-0 cell line and was significantly decreased following transfection with $100 \mathrm{nM}$ siRNA $(\mathrm{P}<0.05)$. CIRP, cold-inducible RNA-binding protein; siRNA, small interfering RNA.

\section{Discussion}

RCC accounts for $\sim 3 \%$ of all adult malignancies. Despite advances in diagnosis, including improved imaging techniques, $20-30 \%$ of RCC patients are diagnosed with mRCC. Patients with mRCC exhibit a median survival time of $\sim 13$ months and the 5 -year survival rate is $<10 \%(17,18)$.
Table I. Cell cycle in two groups following transfection for $48 \mathrm{~h}(\% \pm \mathrm{s})$.

\begin{tabular}{lccc}
\hline Group & G0/G1 & $\mathrm{S}$ & $\mathrm{G} 2 / \mathrm{M}$ \\
\hline siCIRP & $71.81 \pm 0.79$ & $24.31 \pm 0.83$ & $4.04 \pm 0.72$ \\
siNC & $70.34 \pm 1.36$ & $24.65 \pm 1.70$ & $5.02 \pm 0.73$ \\
\hline
\end{tabular}

There was no significant difference between the two groups $(\mathrm{P}>0.05)$. si, small interfering RNA; CIRP, cold-inducible RNA-binding protein; NC, negative control; s, standard deviation.

Immunotherapies (interleukin- 2 and interferon- $\alpha$ ) were considered to be the standard treatment for $\mathrm{mRCC}$ prior to 2005. Since 2005, targeted therapies have involved vascular endothelial growth factor and the mechanistic target of rapamycin in cases where patients with RCC are unable to undergo surgical therapy and these alternatives have been proven to be effective in the treatment of RCC, particularly in the treatment of mRCC. However, $20-25 \%$ of patients with metastatic disease, also known as 'primary resistant' disease, do not respond to any of the available treatments, leading to a rapidly evolving disease with a poor prognosis. These cases require further attention in order to identify novel effective treatment strategies. The present study aimed to provide novel information regarding adjuvant therapies for these aforementioned cases by studying the effect of CIRP on RCC in vitro.

Since CIRP was first isolated in 1997, a number of studies have demonstrated that it serves important roles in numerous physiological and pathological processes. CIRP may be induced by a number of factors, including mild/cold temperatures, DNA damage and hypoxia $(3,19)$. CIRP may protect spermatogenesis against the DNA damage induced by ultraviolet irradiation $(20,21)$. However, an increasing volume of evidence has indicated that CIRP may be involved in the development of tumors. CIRP was revealed to be overexpressed in oral squamous cell carcinoma (OSCC) and pituitary adenoma, and was demonstrated to be involved in the development of liver cancer $(10,12,13)$.

The present study used RT-qPCR, IHC and western blot analysis to detect the expression of CIRP in RCC tissues. The results demonstrated that there were marked differences between expression levels in RCC and peri-cancerous tissues. A total of 13/17 (76.50\%) tumor samples exhibited positive IHC staining for CIRP, compared with the peri-cancerous tissues $(\mathrm{P}<0.05)$ and the most common pathological type was clear cell RCC (92.30\%). Furthermore, 11/14 clear cell RCC samples $(11 / 14,78.57 \%)$ exhibited positive CIRP mRNA levels. These observations were also confirmed in CIRP protein expression levels, as determined by western blot analysis. IHC staining indicated that CIRP was located in the cell cytoplasm. Previous studies have revealed that CIRP was located in the cell cytoplasm in OSCC and endometrial carcinoma (5), and in the cell cytoplasm and cell nucleus of healthy testicular cells (2). The fact that CIRP is located in different organs in different tumors may indicate its different functions. Solid tumors, including RCC, require a rich blood supply, which may result in an increase in the temperature of the tumor 

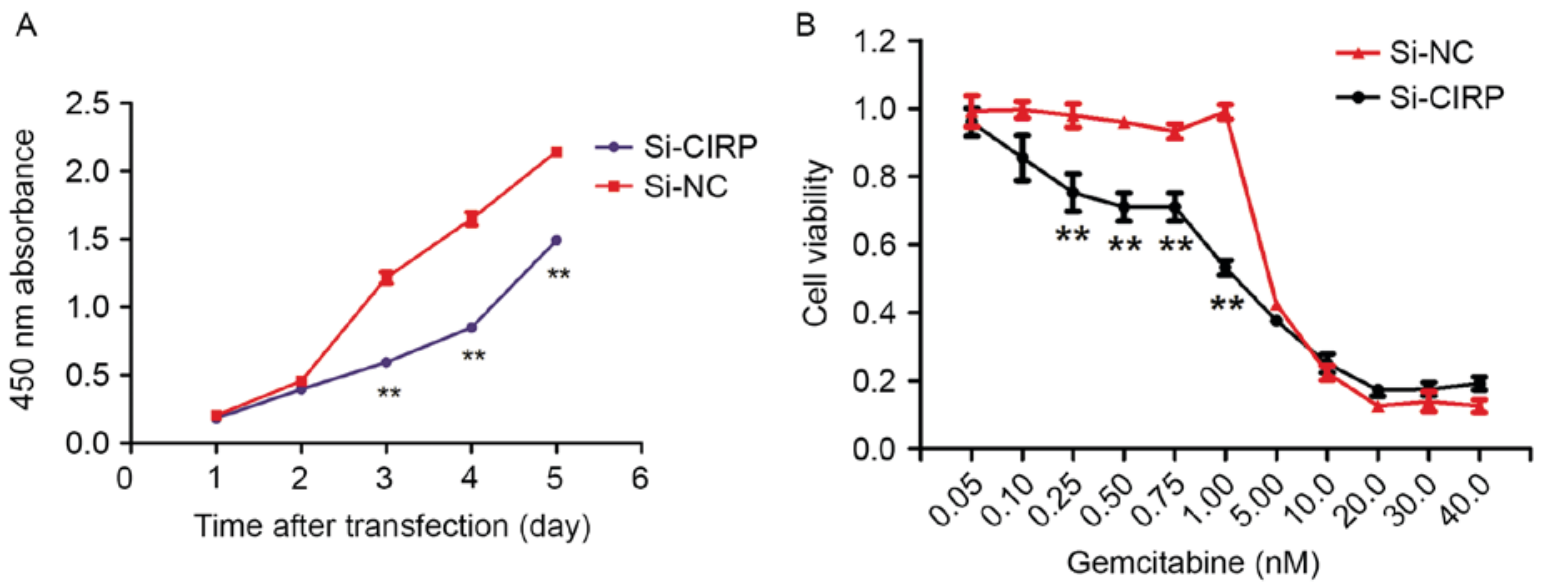

Figure 5. The effect of CIRP siRNA transfection on the chemosensitivity of 786-0 cells to gemcitabine. (A) Cell proliferation 1-5 days after transfection as determined by a WST-1 assay. The cell proliferation of the siCIRP group was significantly reduced compared with the siNC group 3 days after transfection $\left({ }^{* *} \mathrm{P}<0.05\right)$. (B) Chemosensitivity of $786-0$ cells to gemcitabine $72 \mathrm{~h}$ after transfection. When the concentration of gemcitabine was between $0.25 \mathrm{and} 1.0 \mathrm{nM}$, this difference was significant $\left({ }^{* *} \mathrm{P}<0.05\right)$. CIRP, cold-inducible RNA-binding protein; siRNA, small interfering RNA; NC, negative control.
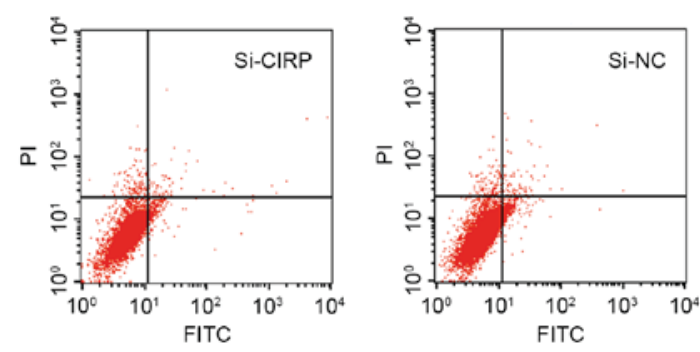

Figure 6. Cell apoptosis of two groups (siCIRP/siNC) following transfection for $48 \mathrm{~h}$. Apoptosis rates were $1.09 \%$ in the siCIRP group and $1.06 \%$ in the siNC group, but these differences were not significant $(\mathrm{P}>0.05)$. si, small interfering RNA; CIRP, cold-inducible RNA-binding protein; NC, negative control.

tissue and, in turn, the downregulation of CIRP. However, the microenvironment of every tumor cell was considered to be severely hypoxic, which may induce overexpression of CIRP. The results of the present study demonstrated that CIRP was overexpressed in RCC (particularly in clear cell RCC).

CIRP mRNA has been revealed to be constitutively expressed in K562, Hep-G2, NC65, HeLa, T24, TERA2 and NEC8 cells (22), and to be involved in ovarian carcinoma (14), testicular carcinoma (23) and prostate cancer (15). In the present study, CIRP was revealed to be constitutively expressed in the clear cell RCC 786-0 cell line. Zeng et al (15) demonstrated that downregulation of cold shock protein genes (including CIRP and RBM3) impairs prostate cancer cell survival and enhances chemosensitivity. A similar phenomenon was observed in the 786-0 cell line in the present study. Furthermore, the present study demonstrated that knockdown of CIRP may inhibit the proliferation of the 786-0 cell line. Additionally, a WST-1 assay was used to detect the cell proliferation ability 1-5 days after transfection, and the results demonstrated that cell proliferation ability in the siCIRP group was significantly decreased $(\mathrm{P}<0.05)$, compared with that in the siNC group. In addition, the chemosensitivity of 786-0 cells to gemcitabine was enhanced in the siCIRP group compared with that in the siNC group. When the concentration of gemcitabine was $>5 \mathrm{nM}$, no differences were observed between the two groups.
Due to the fact that the 786-0 cells had become damaged, continually increasing the drug concentration did not cause the cell survival rate to change significantly.

Xun et al (24) demonstrated that CIRP may regulate the cell cycle regulator cyclin E1, which is aberrantly expressed in a variety of human cancer types and is associated with a poor outcome in breast cancer. In the present study, CIRP had little impact on the cell cycle and cell apoptosis. Cells were transfected with siCIRP or siNC, and were cultured for $48 \mathrm{~h}$, prior to flow cytometry being used to detect the impact of CIRP on the cell cycle and cell apoptosis. No significant differences were observed in the cell cycle or cell apoptosis between the two groups (siCIRP/siNC). Therefore, it was concluded that CIRP may inhibit cell proliferation through other signaling pathways, rather than by altering cell cycle or cell apoptosis. Zeng et al (15) revealed that CIRP knockdown significantly $(\mathrm{P}<0.05)$ inhibited the activation of $\mathrm{p} 53-\mathrm{p} 21$ proteins and increased $\gamma$-H2A.X expression under chemical stress in LNCaP cells, and also enhanced DNA damage and cytotoxic killing in PC-3 cells, in which p53 regulation is deficient. This suggested that CIRP inhibited cell proliferation through the p53-independent pathway. Lujan et al (25) observed decreased proliferation during the lactational switch in mammary glands, but CIRP did not affect apoptosis during mammary gland involution, suggesting a potential in vivo function in suppressing proliferation during a specific developmental transition.

In conclusion, the present study demonstrated that CIRP was overexpressed in RCC tissues and in the RCC 786-0 cell line. The knockdown of CIRP by siRNA inhibited the proliferation of the 786- 0 cell line and enhanced the chemosensitivity of these cells to gemcitabine. These observations suggested a potential novel mechanistic pathway for RCC therapy. However, the precise mechanisms underpinning the effect of CIRP downregulation on the inhibition of cell proliferation remain unclear and require further elucidation.

\section{Acknowledgements}

Not applicable. 


\section{Funding}

This study was supported by the Project of Technological Innovation Planning in Ningbo, China (grant no. YinKe 2012-104).

\section{Availability of data and materials}

The datasets used and/or analyzed during the current study are available from the corresponding author on reasonable request.

\section{Authors' contributions}

GW designed the study. WZ collected clinical specimens. $\mathrm{KZ}$ and $\mathrm{KJ}$ performed the experiments and wrote the manuscript. All authors read and approved the final manuscript.

\section{Ethics statement and consent to participate}

The present study was approved by the Ethics and Scientific Committee of Ningbo Urology and Kidney Hospital and written informed consent was obtained from all participants.

\section{Consent for publication}

All patients volunteered to participate in the study and agreed for the data to be used in academic exchange and publication.

\section{Competing interests}

The authors declare that they have no competing interests.

\section{References}

1. Buti S, Bersanelli M, Sikokis A, Maines F, Facchinetti F, Bria E, Ardizzoni A, Tortora G and Massari F: Chemotherapy in metastatic renal cell carcinoma today? A systematic review. Anticancer Drugs 24: 535-554, 2013.

2. Nishiyama H, Itoh $\mathrm{K}$, Kaneko $\mathrm{Y}$, Kishishita M, Yoshida O and Fujita J: A glycine-rich RNA-binding protein mediating cold-inducible suppression of mammalian cell growth. J Cell Biol 137: 899-908, 1997.

3. Wellmann S, Buhrer C, Moderegger E, Zelmer A, Kirschner R, Koehne P, Fujita J and Seeger K: Oxygen-regulated expression of the RNA-binding proteins RBM3 and CIRP by a HIF-1-independent mechanism. J Cell Sci 117: 1785-1794, 2004.

4. De Leeuw F, Zhang T, Wauquier C, Huez G, Kruys V and Gueydan C: The cold-inducible RNA-binding protein migrates from the nucleus to cytoplasmic stress granules by a methylation-dependent mechanism and acts as a translational repressor. Exp Cell Res 313: 4130-4144, 2007.

5. Yang $\mathrm{C}$ and Carrier F: The UV-inducible RNA-binding protein A18 (A18 hnRNP) plays a protective role in the genotoxic stress response. J Biol Chem 276: 47277-47284, 2001.

6. Sakurai T, Itoh K, Higashitsuji H, Nonoguchi K, Liu Y, Watanabe H, Nakano T, Fukumoto M, Chiba T and Fujita J: Cirp protects against tumor necrosis factor-alpha-induced apoptosis via activation of extracellular signal-regulated kinase. Biochim Biophys Acta 1763: 290-295, 2006.

7. Nishiyama H, Xue JH, Sato T, Fukuyama H, Mizuno N, Houtani T, Sugimoto T and Fujita J: Diurnal change of the cold-inducible RNA-binding protein (Cirp) expression in mouse brain. Biochem Biophys Res Commun 245: 534-538, 1998.

8. Peng Y, Yang PH, Tanner JA, Huang JD, Li M, Lee HF, Xu RH, Kung HF and Lin MC: Cold-inducible RNA binding protein is required for the expression of adhesion molecules and embryonic cell movement in Xenopus laevis. Biochem Biophys Res Commun 344: 416-424, 2006.
9. Lleonart ME: A new generation of proto-oncogenes: Cold-inducible RNA binding proteins. Biochim Biophys Acta 1805: 43-52, 2010.

10. Ren WH, Zhang LM, Liu HQ, Gao L, Chen C, Qiang C, Wang XL, Liu CY, Li SM, Huang C, et al: Protein overexpression of CIRP and TLR4 in oral squamous cell carcinoma: An immunohistochemical and clinical correlation analysis. Med Oncol 31: 120, 2014

11. Hamid AA, Mandai M, Fujita J, Nanbu K, Kariya M, Kusakari T, Fukuhara K and Fujii S: Expression of cold-inducible RNA-binding protein in the normal endometrium, endometrial hyperplasia, and endometrial carcinoma. Int J Gynecol Pathol 22: 240-247, 2003.

12. Wang M, Zhang H, Heng X, Pang Q and Sun A: Expression of cold-Inducible RNA-binding protein (CIRP) in pituitary adenoma and its relationships with tumor recurrence. Med Sci Monit 21: 1256-1260, 2015.

13. Sakurai T, Yada N, Watanabe T, Arizumi T, Hagiwara S, Ueshima K, Nishida N, Fujita J and Kudo M: Cold-inducible RNA-binding protein promotes the development of liver cancer. Cancer Sci 106: 352-358, 2015.

14. Nishiyama H, Higashitsuji H, Yokoi H, Itoh K, Danno S, Matsuda $T$ and Fujita J: Cloning and characterization of human CIRP (cold-inducible RNA-binding protein) cDNA and chromosomal assignment of the gene. Gene 204: 115-120, 1997.

15. Zeng $\mathrm{Y}$, Kulkarni $\mathrm{P}$, Inoue $\mathrm{T}$ and Getzenberg $\mathrm{RH}$ : Down-regulating cold shock protein genes impairs cancer cell survival and enhances chemosensitivity. J Cell Biochem 107: 179-188, 2009.

16. Livak KJ and Schmittgen TD: Analysis of relative gene expression data using real-time quantitative PCR and the 2(-Delta Delta C(T)) method. Methods 25: 402-408, 2001.

17. Cohen HT and McGovern FJ: Renal-cell carcinoma. N Engl J Med 353: 2477-2490, 2005.

18. Dutcher JP, Mourad WF and Ennis RD: Integrating innovative therapeutic strategies into the management of renal cell carcinoma. Oncology (Williston Park) 26: 526-530, 532, 534, 2012.

19. Xue JH, Nonoguchi K, Fukumoto M, Sato T, Nishiyama H, Higashitsuji $\mathrm{H}$, Itoh $\mathrm{K}$ and Fujita J: Effects of ischemia and $\mathrm{H} 2 \mathrm{O} 2$ on the cold stress protein CIRP expression in rat neuronal cells. Free Radic Biol Med 27: 1238-1244, 1999.

20. Zhou KW, Zheng XM, Yang ZW, Zhang L and Chen HD: Overexpression of CIRP may reduce testicular damage induced by cryptorchidism. Clin Invest Med 32: E103-E111, 2009.

21. Sheikh MS, Carrier F, Papathanasiou MA, Hollander MC, Zhan Q, Yu K and Fornace AJ Jr: Identification of several human homologs of hamster DNA damage-inducible transcripts cloning and characterization of a novel UV-inducible cDNA that codes for a putative RNA-binding protein. J Biol Chem 272: 26720-26726, 1997.

22. Artero-Castro A, Callejas FB, Castellvi J, Kondoh H, Carnero A, Fernández-Marcos PJ, Serrano M, Ramón y Cajal S and Lleonart ME: CIRP bypasses replicative senescence in primary cells through ERK1/2 activation. Mol Cell Biol 29: 1855-1868, 2009.

23. Coffey DS, Getzenberg RH and DeWeese TL: Hyperthermic biology and cancer therapies: A hypothesis for the 'Lance Armstrong effect'. JAMA 296: 445-448, 2006.

24. Xun G, Wu Y and Hartley RS: Cold-inducible RNA-binding protein contributes to human antigen $\mathrm{R}$ and cyclin E1 deregulation in breast cancer. Mol Carcinog 49: 130-140, 2010.

25. Lujan DA, Garcia S, Vanderhoof J, Sifuentes J, Brandt Y, Wu Y, Guo X, Mitchell T, Howard T, Hathaway HJ and Hartley RS: Cold-inducible RNA binding protein in mouse mammary gland development. Tissue Cell 48: 577-587, 2016.

This work is licensed under a Creative Commons Attribution-NonCommercial-NoDerivatives 4.0 International (CC BY-NC-ND 4.0) License. 